\title{
Skeletal muscle and plasma concentrations of cefazolin during cardiac surgery in infants
}

\author{
Adam S. Himebauch, MD, ${ }^{\text {a,b }}$ Susan C. Nicolson, MD, ${ }^{\mathrm{a}}$ Martha Sisko, BSN, RN, MS, CCRC, ${ }^{\mathrm{a}}$ \\ Ganesh Moorthy, PhD, ${ }^{b}$ Stephanie Fuller, MD, ${ }^{c}$ J. William Gaynor, MD, ${ }^{c}$ Athena F. Zuppa, MD, MSCE, ${ }^{a, b}$ \\ Elizabeth Fox, MD, ${ }^{\text {b,d }}$ and Todd J. Kilbaugh, $\mathrm{MD}^{\mathrm{a}}$
}

Objective: To describe the pharmacokinetics and tissue disposition of prophylactic cefazolin into skeletal muscle in a pediatric population undergoing cardiac surgery.

\begin{abstract}
Methods: The subjects included 12 children, with a median age of 146 days (interquartile range, 136-174) and median weight of $5.5 \mathrm{~kg}$ (interquartile range, 5.2-7.3) undergoing cardiac surgery and requiring cardiopulmonary bypass with or without deep hypothermic circulatory arrest. Institutional cefazolin at standard doses of $25 \mathrm{mg} / \mathrm{kg}$ before incision and $25 \mathrm{mg} / \mathrm{kg}$ in the bypass prime solution were administered. Serial plasma and skeletal muscle microdialysis samples were obtained intraoperatively and the unbound cefazolin concentrations measured. Noncompartmental pharmacokinetic analyses were performed and the tissue disposition evaluated.

Results: After the first dose of cefazolin, the skeletal muscle concentrations peaked at a median microdialysis collection interval of 30 to 38.5 minutes. After the second dose, the peak concentrations were delayed a median of 94 minutes in subjects undergoing deep hypothermic circulatory arrest. Skeletal muscle exposure to cefazolin measured by the area under concentration time curve 0-last measurement was less in the subjects who underwent deep hypothermic circulatory arrest than in those who received cardiopulmonary bypass alone $(P=.04)$. The skeletal muscle concentrations of cefazolin exceeded the goal concentrations for methicillin-sensitive Staphylococcus aureus prophylaxis; however, the goal concentrations for gram-negative pathogens associated with surgical site infections were achieved only $42.1 \%$ to $84.2 \%$ and $0 \%$ to $11.2 \%$ of the intraoperative time in subjects undergoing cardiopulmonary bypass alone or deep hypothermic circulatory arrest, respectively.
\end{abstract}

Conclusions: This cefazolin dosing strategy resulted in skeletal muscle concentrations that are likely not effective for surgical prophylaxis against gram-negative pathogens but are effective against methicillinsensitive $S$ aureus in infants undergoing cardiac surgery. (J Thorac Cardiovasc Surg 2014;148:2634-41)

Cardiopulmonary bypass (CPB) with or without deep hypothermic circulatory arrest (DHCA) can have physiologic alterations that affect drug pharmacokinetics (PK) and drug disposition. ${ }^{1,2}$ In neonatal and infant populations, these PK changes are likely exacerbated, given the larger ratio of $\mathrm{CPB}$ priming volume to patient circulating volume and varying degrees of organ

From the Department of Anesthesiology and Critical Care Medicine, ${ }^{\mathrm{a}}$ Center for Clinical Pharmacology, ${ }^{\mathrm{b}}$ Division of Cardiothoracic Surgery, ${ }^{\mathrm{c}}$ Department of Surgery, and Division of Oncology, ${ }^{\mathrm{d}}$ Department of Pediatrics, University of Pennsylvania Perelman School of Medicine and The Children's Hospital of Philadelphia, Philadelphia, Pa.

The present study was supported by the Department of Anesthesiology and Critical Care Medicine, The Children's Hospital of Philadelphia, Philadelphia, Pa. Dr Himebauch was supported by the National Institutes of Health, United States (grant T32GM007612-34) for much of this study.

Disclosures: Authors have nothing to disclose with regard to commercial support.

Received for publication April 20, 2014; revisions received May 30, 2014; accepted for publication June 5, 2014; available ahead of print Aug 15, 2014.

Address for reprints: Todd J. Kilbaugh, MD, Department of Anesthesiology and Critical Care Medicine, University of Pennsylvania Perelman School of Medicine, The Children's Hospital of Philadelphia, Main Building, Suite 7C26, 34th St and Civic Center Blvd, Philadelphia, PA 19104 (E-mail: kilbaugh@email.chop.edu). 0022-5223/\$36.00

Copyright (c) 2014 by The American Association for Thoracic Surgery

http://dx.doi.org/10.1016/j.jtcvs.2014.06.064 maturation. ${ }^{1}$ These factors can alter the blood and tissue concentrations of medications, including the prophylactically administered antibiotics used to help prevent surgical site infections (SSIs).

Pediatric cardiac surgical patients have estimated SSI rates of 1.7 to 8.0 per 100 cases. $^{3-9}$ Major postoperative infections in these populations have been shown to increase both the hospital length of stay and the mortality. ${ }^{8}$ Existing published data have identified procedure-related factors, including intraoperative hypothermia, incorrect timing of preoperative antibiotic administration, and surgery duration, and patient-related factors that place some children undergoing cardiac surgery at greater risk of SSIs. ${ }^{3-13}$ Although most bacterial pathogens causing SSIs in this population are gram-positive organisms, gramnegative bacteria have been responsible for a significant proportion of emerging infections. ${ }^{3-7,9-12,14}$

Critical for the prevention of SSIs is the use of a dosing schedule of prophylactic antibiotics that achieves and maintains adequate tissue concentrations of antibiotics near the surgical site. ${ }^{15-17}$ Microdialysis is a minimally invasive method used in clinical pharmacology to directly and continuously sample free, unbound analyte concentrations 


\section{Abbreviations and Acronyms \\ AUC = area under the concentration time curve \\ $\mathrm{CPB}=$ cardiopulmonary bypass \\ DHCA $=$ deep hypothermic circulatory arrest \\ MIC = minimum inhibitory concentration \\ $\mathrm{PD}=$ pharmacodynamics \\ $\mathrm{PK}=$ pharmacokinetics \\ $\mathrm{RR} \quad=$ relative recovery \\ SSI = surgical site infection}

in the interstitial fluid of various tissues. ${ }^{18,19}$ PK studies of prophylactic antibiotics during CPB in children have used both total and unbound plasma concentrations as a surrogate for the tissue drug concentrations. ${ }^{20-23}$ However, the plasma concentrations might not accurately reflect the antimicrobial exposures in the tissue where an infection occurs. Tissue concentrations might represent the true target for SSI prevention and could be important to better determine the recommendations for prophylactic antibiotic dosing.

The purpose of the present study was to determine the PK and tissue disposition into the skeletal muscle of prophylactic cefazolin, a commonly used first-generation cephalosporin, using both plasma sampling and microdialysis sampling in skeletal muscle in a homogeneous population of infants with single ventricle physiology undergoing CPB with and without DHCA.

\section{METHODS}

\section{Subjects and Surgical Procedure}

The institutional review board at The Children's Hospital of Philadelphia approved the present PK study. The study protocol met all applicable safety and reporting guidelines, with informed consent obtained from the legal guardians of all subjects.

Children with single ventricle physiology who received cefazolin during a procedure involving superior vena cava-pulmonary anastomosis without pre-existing renal or hepatic dysfunction and no established allergy to cefazolin were eligible. The anesthetic technique was at the discretion of the attending cardiac anesthesiologist but generally included premedication with oral pentobarbital, induction of anesthesia with sevoflurane in nitrous oxide/oxygen, and maintenance of anesthesia with isoflurane, fentanyl, pancuronium or vecuronium, and dexmedetomidine. The cefazolin dosing schedule used was institutional standard-of-care at the study procedures and was as follows: $25 \mathrm{mg} / \mathrm{kg}$ given intravenously within 1 hour before incision and $25 \mathrm{mg} / \mathrm{kg}$ added to the CPB priming volume (referred to henceforth as the "second dose" or "dose 2").

\section{Description of CPB Procedures}

All patients underwent CPB, with 7 patients also receiving DHCA. The patients received heparin $(200 \mathrm{U} / \mathrm{kg})$ before initiation of $\mathrm{CPB}$, with an activating clotting time target of $>480$ seconds (Hemochron Response; International Technidyne Corp, Edison, NJ). The CPB circuits were primed with PLASMA-LYTE A (Baxter International, Deerfield, Ill), 25\% albumin, sodium bicarbonate, calcium gluconate, heparin sodium, furosemide, pancuronium, or vecuronium, with or without aminocaproic acid, whole blood, packed red blood cells, and cefazolin $(25 \mathrm{mg} / \mathrm{kg})$.
All patients received methylprednisolone before $\mathrm{CPB}$ or in the $\mathrm{CPB}$ prime and mannitol after crossclamp removal. The extracorporeal circuits consisted of a membrane oxygenator (CAPIOX RX05 Baby RX or CAPIOX RX15; Terumo, Tokyo, Japan), polyvinylchloride tubing (Terumo), and roller pumps (Jostra HL 20; Maquet, Rastatt, Germany; or Stöckert SIII; Sorin Group, Milan, Italy). For DHCA, hypothermia was induced for 15 to 20 minutes to a target venous temperature of $18^{\circ} \mathrm{C}$ with rewarming for 22 to 25 minutes after reinitiation of CPB. Modified ultrafiltration was performed after separation from CPB in all patients.

\section{PK Sampling}

Blood samples ( $2 \mathrm{~mL}$ of blood collected in lithium heparin tubes) were obtained from a site separate from that of cefazolin administration by way of either an existent arterial catheter or from the CPB circuit. Microdialysate samples were collected continuously throughout the operative procedure. The blood and microdialysate samples were collected simultaneously at times relative to each cefazolin dose (before the dose and $5,15,30,60,90$, and 120 minutes after), immediately before and after DHCA (if DHCA was used), and at sternum and skin closure. The plasma samples were separated into 2 aliquots: 1 to measure the total (protein bound plus unbound) cefazolin concentration and 1 to measure the unbound cefazolin concentration.

\section{Microdialysis Description}

Microdialysis was performed using linear microdialysis catheters (66 Linear Catheter; M Dialysis AB, Solna, Sweden) inserted percutaneously into the left deltoid muscle after the induction of anesthesia and was removed after skin closure before the patient's emergence from anesthesia. The deltoid muscle was chosen for sample collection accessibility during surgery and represents disposition of cefazolin into a skeletal muscle. The catheters had polyarylethersulfone membranes with a molecular weight cutoff of 20,000 Daltons and $10 \mathrm{~mm}$ length. The fluid used to perfuse the microdialysis catheter was an isotonic solution designed for use in peripheral tissue (Perfusion Fluid T1; M Dialysis AB). A 107 Microdialysis Pump (M Dialysis $\mathrm{AB}$ ) with a flow rate of $1 \mu \mathrm{L} / \mathrm{min}$ was used for microdialysate sample collection.

\section{Relative Recovery and Interstitial Fluid Concentration Calculations}

The in vivo relative recovery (RR) of cefazolin in each microdialysis catheter was calculated using retrodialysis. For retrodialysis, the perfusion fluid was prepared by our Investigational Pharmacy and contained $20 \mu \mathrm{g} / \mathrm{mL}$ of cefazolin and was run with a perfusion rate of $1 \mu \mathrm{L} / \mathrm{min}$ for 30 minutes before collection of the retrodialysis sample. The in vivo RR was calculated for each subject using the following equation ${ }^{19}$ :

$$
\text { In vivo }(\mathrm{RR})(\%)=100-\left(100 \times \mathrm{C}_{\text {dialysate }} / \mathrm{C}_{\text {perfusate }}\right) .
$$

where $\mathrm{C}_{\text {dialysate }}$ is the cefazolin concentration in the retrodialysis sample and $\mathrm{C}_{\text {perfusate }}$ is the concentration of cefazolin in the perfusion fluid that was run during retrodialysis. After retrodialysis, the catheters were flushed with the Perfusion Fluid T1 (not containing cefazolin) followed by a median equilibration period of 21.5 minutes (interquartile range [IQR], 19.0-26.0 minutes) at a flow rate of $1 \mu \mathrm{L} / \mathrm{min}$ before the administration of the first dose of cefazolin. The interstitial concentration of cefazolin was then calculated using the following equation:

Interstitial Concentration $=100$

$\times$ (concentration in microdialysate/in vivo RR),

where the concentration in the microdialysate is the cefazolin concentration measured in the collected specimens. 


\section{Sample Analysis}

The blood samples were centrifuged at $2500 \mathrm{rpm}$ for 10 minutes, separated into 2 aliquots, stored at $-20^{\circ} \mathrm{C}$ at collection, and then stored at $-80^{\circ} \mathrm{C}$. One aliquot was processed further by ultrafiltration of $400 \mu \mathrm{L}$ of plasma with a Spin-X ultrafiltrate membrane $(10,000$ molecular weight cutoff; Corning Inc, Lowell, Mass) to measure unbound cefazolin. Nonspecific binding of cefazolin to the ultrafiltration membrane was $12 \%$, and this was corrected for in the final calculations. Two unbound plasma concentrations (total of 120 measurement points) were estimated according to the average protein binding for other similar samples.

The cefazolin concentrations in the microdialysate (unbound only) and plasma samples (total and unbound) were determined using validated assays $^{24}$ and high-performance liquid chromatography and tandem mass spectrometry developed and performed at The Children's Hospital of Philadelphia. Total plasma samples $(25 \mu \mathrm{L})$ were mixed with an internal standard solution $(5 \mu \mathrm{g} / \mathrm{mL}$ ampicillin in water) before protein precipitation with $500 \mu \mathrm{L}$ cold methanol and then diluted with $500 \mu \mathrm{L}$ water before centrifugation. Next, $100 \mu \mathrm{L}$ of the supernatant was placed onto a 96-well plate. Unbound plasma samples and microdialysate samples were assayed for cefazolin by adding $10 \mu \mathrm{L}$ of these samples directly to a 96-well plate followed by $500 \mu \mathrm{L}$ of the internal standard ( $40 \mathrm{ng} / \mathrm{mL}$ ampicillin in water). For all samples, the high-performance liquid chromatography injection volume was $5 \mu \mathrm{L}$, and chromatographic separation was achieved using a HyPurity C18 Column $(50 \times 2.1 \times 3 \mu \mathrm{m}$; Thermo Scientific, Waltham, Mass), with mobile phase A consisting of $5 \mathrm{mM}$ ammonium acetate in water ( $\mathrm{pH} 4.7$ ) and mobile phase $\mathrm{B}$ consisting of $5 \mathrm{mM}$ ammonium acetate in 90/10 acetonitrile/water. Cefazolin and ampicillin were detected using an API4000 Qtrap mass spectrometer (AB Sciex, Redwood City, Calif). The lower limit of quantification for the total plasma assay was $1 \mu \mathrm{g} / \mathrm{mL}$ (linear range, 1-500), with inter- and intraday coefficients of variation of $<5 \%$. For the unbound cefazolin, the lower limit of quantification was $0.1 \mu \mathrm{g} / \mathrm{mL}$ (linear range, 0.1-100), with inter- and intraday coefficients of variation of $<5 \%$.

\section{PK and Statistical Analysis}

Noncompartmental methods were used for the PK analyses. The maximum plasma and skeletal muscle concentration (Cmax) and the time to the maximum concentration were determined after each cefazolin dose. Owing to the nature of the microdialysis collection, the Cmax for the microdialysis samples represented the average concentrations during the collecting interval.

The area under the concentration time curve (AUC) for the plasma samples was calculated using the log-linear trapezoid method. For the microdialysis samples, the skeletal muscle AUC was calculated by multiplying the measured unbound cefazolin concentration corrected for $\mathrm{RR}$ by the interval of the microdialysis sample collection and then the summation of the areas for each interval. Calculation of the AUC from 0 to the last measurement $\left(\mathrm{AUC}_{0 \text {-last }}\right)$ allows for a measure of cefazolin exposure in both plasma and skeletal muscle for the duration of the intraoperative sample collection period. Tissue penetration of cefazolin was determined by calculating, and comparing, the ratios of $\mathrm{AUC}_{0 \text {-last }}$ for the microdialysis samples to the $\mathrm{AUC}_{0 \text {-last }}$ for the unbound plasma samples.

The PK-pharmacodynamic (PD) factor most closely associated with the antibacterial effectiveness of cephalosporins is the amount of time the concentration of the free drug exceeds the minimum inhibitory concentration (MIC) for bacterial growth $(f \mathrm{~T}>\mathrm{MIC}){ }^{25}$ Therefore, this value was calculated using the relevant MIC required to inhibit the growth of $90 \%$ of organisms $\left(\mathrm{MIC}_{90}\right.$ ) values. ${ }^{26}$

The summary data are presented as the median and IQR. Nonparametric tests, including the Wilcoxon signed rank test and the Wilcoxon rank sum test, were used for comparison statistics. Statistical analyses and plots were performed using R (R Project for Statistical Computing, Vienna, Austria),
Microsoft Excel (Microsoft, Redmond, Wash), and S-PLUS (TIBCO Software, Inc, Palo Alto, Calif).

\section{Safety and Monitoring}

Each subject had a microdialysis adverse event monitoring form completed after catheter placement and daily until hospital discharge or $\leq 7$ days postoperatively to assess for complications related to the microdialysis catheters.

\section{RESULTS \\ Population Characteristics}

A convenience sample of 14 subjects was enrolled in the present study, with complete data obtained from 12 (Table 1). For 1 subject, the microdialysis catheter did not function, and no microdialysate or blood samples were collected, and 1 subject had not received the correct cefazolin dose. No SSIs developed in the present cohort.

\section{PK Parameters}

The timing and duration of CPB and DHCA varied for every patient. After administration of the first cefazolin dose, the unbound plasma cefazolin concentrations had peaked at the first measured point ( $\mathrm{Cmax} 1$ and time to maximum concentration 1) and then had decreased exponentially. The minimum concentration measured before dose 2 was $13.5 \mu \mathrm{g} / \mathrm{mL}$ (IQR, 10.9-16.0). The second dose was administered 37.5 minutes (IQR, 31.8-49.0) after the initial dose and produced a second unbound plasma peak of similar concentration (Cmax2) and time (time to the maximum concentration 2) to the first dose (Table 2, Figure 1).

After administration of the first cefazolin dose, the muscle concentrations of cefazolin started to increase within 5 to 15 minutes but had not peaked until 30 to 45 minutes for both groups (Table 2, Figure 2). However, after the second cefazolin dose, peak muscle concentrations were observed at a median of 31 to 52 minutes for the CPB-only group and were delayed to a median of 94 minutes for the CPB plus DHCA group (Table 2). After the first cefazolin dose, both groups had similar calculated clearances (Table 2); however, the calculated clearance (determined from the total dose received) during the study period was decreased in the subjects who had undergone CPB plus DHCA (Table 2, Figure 1).

\section{Tissue Penetration}

The median in vivo RR was $28.6 \%$ (IQR, $21.5 \%$ $30.8 \%$ ). The skeletal muscle to unbound plasma $\mathrm{AUC}_{0 \text {-last }}$ ratio was significantly less in the $\mathrm{CPB}$ plus DHCA group than in the $\mathrm{CPB}$-only group. This was driven by the greater unbound plasma $\mathrm{AUC}_{0 \text {-last }}$ in the $\mathrm{CPB}$ plus DHCA group (Table 2), indicating delayed plasma clearance. 
TABLE 1. Subject characteristics $(n=12)$

\begin{tabular}{|c|c|c|c|}
\hline Variable & $\begin{array}{c}\text { CPB } \\
(n=5)\end{array}$ & $\begin{array}{c}\text { CPB + DHCA } \\
(\mathbf{n}=7)\end{array}$ & $\begin{array}{c}P \\
\text { value }\end{array}$ \\
\hline Age $(d)$ & & & .53 \\
\hline Median & 141 & 160 & \\
\hline IQR & $129-150$ & $140-184$ & \\
\hline Sex & & & .56 \\
\hline Male & 2 & 5 & \\
\hline Female & 3 & 2 & \\
\hline Weight (kg) & & & 1 \\
\hline Median & 5.5 & 5.8 & \\
\hline IQR & $4.9-7.2$ & $5.4-7.3$ & \\
\hline Length (m) & & & .87 \\
\hline Median & 0.61 & 0.63 & \\
\hline IQR & $0.59-0.67$ & $0.58-0.65$ & \\
\hline $\begin{array}{c}\text { Interval from cefazolin dose } \\
1 \text { to incision (min) }\end{array}$ & & & .81 \\
\hline Median & 5.5 & 5.5 & \\
\hline IQR & $4.5-9.0$ & $3.3-7.8$ & \\
\hline $\begin{array}{l}\text { Interval from cefazolin dose } \\
1 \text { to dose } 2 \text { (min) }\end{array}$ & & & .20 \\
\hline Median & 35.0 & 40.0 & \\
\hline IQR & $30.0-39.0$ & $34.0-59.0$ & \\
\hline Actual cefazolin dose $1(\mathrm{mg} / \mathrm{kg})$ & & & .22 \\
\hline Median & 25.3 & 25.0 & \\
\hline IQR & $25.0-25.5$ & $25.0-25.1$ & \\
\hline Actual cefazolin dose $2(\mathrm{mg} / \mathrm{kg})$ & & & .39 \\
\hline Median & 25.0 & 25.0 & \\
\hline IQR & $25.0-25.1$ & $25.0-25.0$ & \\
\hline CPB prime volume $(\mathrm{mL})$ & & & .37 \\
\hline Median & 450 & 425 & \\
\hline IQR & $430-500$ & $400-437$ & \\
\hline CPB or total support time (min) & & & .03 \\
\hline Median & 35.7 & 64.1 & \\
\hline IQR & $33.0-38.4$ & $60.3-92.6$ & \\
\hline DHCA time (min) & & & - \\
\hline Median & NA & 24.8 & \\
\hline IQR & & $22.0-44.4$ & \\
\hline Total surgical time (min) & & & .09 \\
\hline Median & 123.8 & 163.0 & \\
\hline IQR & $99.3-153.9$ & $126.7-437.5$ & \\
\hline Procedure start temperature $\left({ }^{\circ} \mathrm{C}\right)$ & & & .93 \\
\hline Median & 36.4 & 36.4 & \\
\hline IQR & $35.9-36.6$ & $35.8-36.7$ & \\
\hline Lowest core temperature $\left({ }^{\circ} \mathrm{C}\right)$ & & & .003 \\
\hline Median & 33.3 & 17.8 & \\
\hline IQR & $33.1-35.8$ & $16.8-18.2$ & \\
\hline Procedure end temperature $\left({ }^{\circ} \mathrm{C}\right)$ & & & .19 \\
\hline Median & 37.2 & 35.9 & \\
\hline $\mathrm{IQR}$ & $36.3-37.2$ & $35.6-36.6$ & \\
\hline Surgical procedures (n) & & & - \\
\hline Bidirectional Glenn & 5 & 1 & \\
\hline Bilateral bidirectional Glenn & 0 & 3 & \\
\hline Kawashima & 0 & 2 & \\
\hline Hemi-Fontan & 0 & 1 & \\
\hline
\end{tabular}

Categorical data were compared using Fisher's exact test and continuous data using the Wilcoxon rank sum test. $C P B$, Cardiopulmonary bypass; $D H C A$, deep hypothermic cardiac arrest; $I Q R$, interquartile range; $N A$, not applicable.

\section{$f \mathbf{T}>$ MIC Value}

For all subjects, approximately $100 \%$ of the sampling period showed unbound cefazolin concentrations in both plasma and skeletal muscle of $>2 \mu \mathrm{g} / \mathrm{mL}$ (Table 3). This percentage decreased for both groups for concentrations $>16 \mu \mathrm{g} / \mathrm{mL}$ and $>32 \mu \mathrm{g} / \mathrm{mL}$ in the plasma or skeletal muscle, respectively. The most pronounced decrease was noted in the skeletal muscle of the subjects who underwent DHCA (Table 3).

\section{Protein Binding}

Cefazolin is known to demonstrate concentrationdependent protein binding. ${ }^{27}$ In the present study, the median percentage of protein binding of cefazolin for all collected plasma samples was $84.8 \%$ (IQR, $79.8 \%-88.0 \%$ ). However, the percentage of protein binding of cefazolin in plasma samples collected during DHCA was $78.9 \%$ (IQR, $77.3 \%-81.9 \%$ ), significantly less than that in those samples collected at other times that showed a median of $85.5 \%$ (IQR, $81.3 \%-88.7 \% ; P=.002$ ).

\section{Microdialysis Catheter Safety}

Of the 12 subjects, 6 experienced minor bleeding (defined as 1-3 drops of blood) on placement of the catheters and 3 experienced minor bleeding on removal. No subjects experienced subcutaneous bleeding during anticoagulation. No complications attributable to the microdialysis catheters occurred for $\leq 7$ days after removal.

\section{DISCUSSION}

The purpose of the present study was to describe the plasma and skeletal muscle PK and tissue disposition of cefazolin in a homogeneous group of young children undergoing open heart surgery with and without DHCA. This is the first published study to use microdialysis in a pediatric surgical population for application in clinical pharmacology.

The cefazolin dosing strategy used during the present study resulted in skeletal muscle concentrations that were likely effective for prophylaxis against methicillinsensitive Staphylococcus aureus ( $\mathrm{MIC}_{90} \geq 2 \mu \mathrm{g} / \mathrm{mL}$ ) throughout procedures that require $\mathrm{CPB}$ with or without DHCA. However, gram-negative organisms and Staphylococcus epidermidis, some of which might be susceptible to cefazolin, comprise a significant proportion of the reported epidemiology of SSIs in pediatric cardiac surgical patients. ${ }^{3-7,9-12,14}$ The dosing regimen used in the present study might be inadequate to prevent infections by those pathogens with an $\mathrm{MIC}_{90}$ of $\geq 32 \mu \mathrm{g} / \mathrm{mL}$ in patients undergoing CPB or by those pathogens with an $\mathrm{MIC}_{90}$ of $\geq 16 \mu \mathrm{g} / \mathrm{mL}$ in patients undergoing $\mathrm{CPB}$ with DHCA. Unlike PD measures of cephalosporin efficacy for treatment of active infections (goal, $4-5 \times \mathrm{MIC}_{90}$ value 
TABLE 2. Pharmacokinetic parameters for cefazolin for all subjects

\begin{tabular}{lccc}
\hline \multicolumn{1}{c}{ Parameter } & All subjects $(\mathbf{n}=\mathbf{1 2})$ & CPB only $(\mathbf{n}=\mathbf{5})$ & CPB + DHCA $(\mathbf{n}=\mathbf{7})$ \\
\hline Tmax1 unbound plasma $(\mathrm{min})$ & $5.0(5.0-6.0)$ & $5.0(5.0-5.0)$ & $6.0(5.5-6.0)$ \\
Cmax1 unbound plasma $(\mu \mathrm{g} / \mathrm{mL})$ & $45.7(35.0-56.4)$ & $40.6(35.3-54.1)$ & $50.7(35.8-58.4)$ \\
Tmax1 MD $(\mathrm{min})$ & $30.5-38.5$ & $30-35$ & $31-45$ \\
Cmax1 MD $(\mu \mathrm{g} / \mathrm{mL})$ & $17.9(8.7-34.1)$ & $31.6(18.9-58.1)$ & $15(8.7-25.5)$ \\
Tmax2 unbound plasma $(\mathrm{min})$ & $5.0(5.0-7.5)$ & $5.0(5.0-5.0)$ & $5.0(5.0-10.0)$ \\
Cmax2 unbound plasma $(\mu \mathrm{g} / \mathrm{mL})$ & $50.9(42.8-60.6)$ & $41.6(36.7-61.3)$ & $52.3(48.8-58.5)$ \\
Tmax2 MD $(\mathrm{min})$ & $64.5-82.5$ & $31-52$ & 94 \\
Cmax2 MD $(\mu \mathrm{g} / \mathrm{mL})$ & $29.6(15.9-60.7)$ & $60(30.0-62.7)$ & $16.5(13.9-42.9)$ \\
MD/unbound plasma AUC ratio & $0.7(0.4-1.2)$ & $1.2 *(0.8-1.3)$ & $0.4 *(0.3-0.7)$ \\
MD AUC 0 -last $(\mu \mathrm{g} \times$ min/mL) & $2432.2(1823.1-5794.8)$ & $3271.1(2512.2-5802.0)$ & $2230.3(1613.18-4072.22)$ \\
Unbound plasma AUC $/$-last $(\mu \mathrm{g} \times \mathrm{min} / \mathrm{mL})$ & $4881.0(3068.2-5480.5)$ & $2883.0 \dagger(2613.6-3129.9)$ & $5063.3 \dagger(4892.4-6830.3)$ \\
Calculated dose 1 clearance $(\mathrm{L} / \mathrm{h} / \mathrm{kg})$ & $1.6(1.4-1.9)$ & $1.7(1.5-2.5)$ & $1.5(1.4-1.7)$ \\
Calculated intraoperative clearance $(\mathrm{L} / \mathrm{h} / \mathrm{kg})$ & $0.6(0.6-1.0)$ & $1.4 \ddagger(1.0-1.2)$ & $0.6 \ddagger(0.4-0.6)$ \\
\hline D & &
\end{tabular}

Data presented as median (IQR), except for the Tmax values for the MD samples. Tmax data for MD samples presented as median values of the time collection interval over which the likely peak was collected, because the measured microdialysate concentrations represent average concentrations over the collected period and not precise point estimates. $C P B$, Cardiopulmonary bypass; $D H C A$, deep hypothermic circulatory arrest; Tmaxl and Tmax2, time to maximum concentration at first and second measured point, respectively; $C \max 1$ and $C \max 2$, maximum concentration at first and second measured point, respectively; $M D$, microdialysis; $A U C$, area under the concentration time curve; $A U C_{0-l a s t}$,

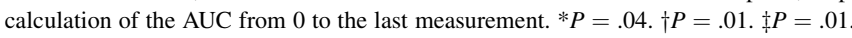

for $60 \%-70 \%$ of the dosing interval ${ }^{25}$ ), no clear guidelines are available for the antibiotic concentrations necessary for prophylactic dosing. Devoid of accepted definitions, our assessment of SSI efficacy was very conservative and based only on the requirement that the skeletal muscle concentrations surpass the $\mathrm{MIC}_{90}$ for $>60 \%$ of the dosing interval. Because the postantibiotic effect of cefazolin is less for gram-negative organisms, ${ }^{25}$ our assessment might be even more of an underestimate for these organisms compared with methicillin-sensitive $S$ aureus.

Because $f \mathrm{~T}>\mathrm{MIC}$ is the most important $\mathrm{PD}$ parameter when assessing cefazolin dosing and bacteria that reside on the skin are the main pathogens causing SSIs, it seems prudent to attempt to achieve adequate tissue concentrations

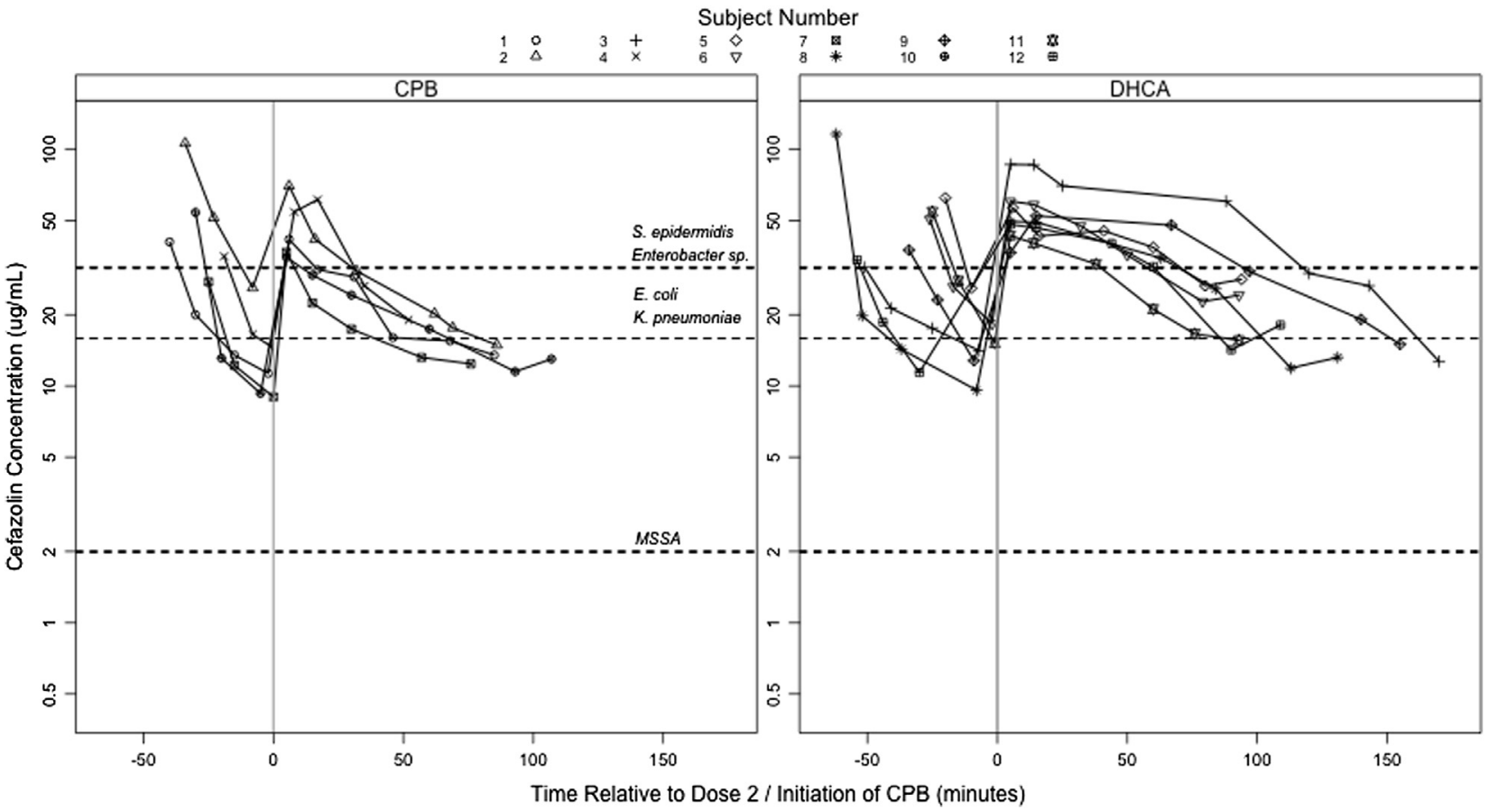

FIGURE 1. Semilogarithmic concentration time profile for unbound cefazolin in plasma of all subjects referenced from the initiation of cardiopulmonary bypass $(C P B)$. The horizontal lines indicate the various concentration targets and associated surgical site infection pathogens. The vertical line indicates the initiation of CPB. DHCA, Deep hypothermic circulatory arrest; E coli, Escherichia coli; K pneumonia, Klebsiella pneumonia; $S$ epidermidis, Staphylococcus epidermidis; MSSA, methicillin-sensitive Staphylococcus aureus. 


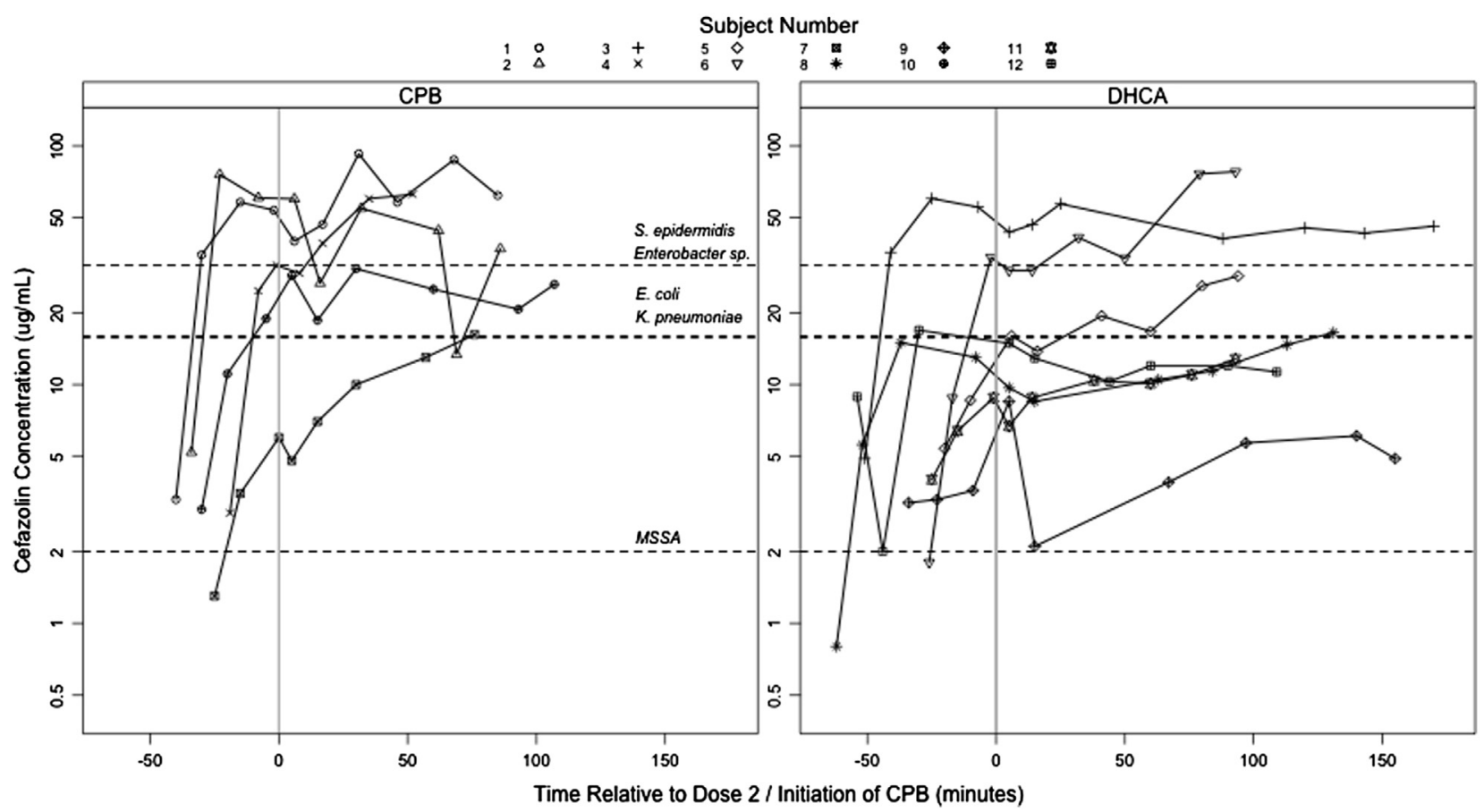

FIGURE 2. Semilogarithmic concentration time profile for unbound cefazolin in skeletal muscle of all subjects referenced from the initiation of cardiopulmonary bypass $(C P B)$. The horizontal lines indicate the various concentration targets and associated surgical site infection pathogens. The vertical line indicates the initiation of CPB. DHCA, Deep hypothermic circulatory arrest; E coli, Escherichia coli; K pneumonia, Klebsiella pneumonia; S epidermidis, Staphylococcus epidermidis; MSSA, methicillin-sensitive Staphylococcus aureus.

of antibiotics before the surgical incision. Our results support the course of increasing tissue concentrations that has been demonstrated in several adult surgical populations. ${ }^{28-30}$ This could partially have resulted from a limitation of microdialysis as a sampling method, because it relies on equilibration across a semimembrane and we were measuring average concentrations for the collection interval. However, we attempted to mitigate this effect during the present study by timing the microdialysis sampling with each plasma sample.

$\mathrm{CPB}$ can change the PK owing to many factors, including hemodilution, differing compositions of prime fluid affecting protein binding, the $\mathrm{pH}$ management strategy used, altered renal and hepatic blood flow resulting in changes in clearance, the effects of hypothermia and circulatory arrest, and the systemic inflammatory reaction induced by CPB. ${ }^{1}$ In addition, sequestration of cefazolin by the CPB circuit might have a significant effect on the available drug for disposition into tissue. ${ }^{31}$ In the present study, the skeletal muscle concentrations were starting to decrease just before or immediately after the initiation of CPB for all patients. After the second dose of cefazolin, the skeletal muscle concentrations again started to increase and was maintained at a value similar to that of the pre-CPB maximum concentration until the end of the procedure in both groups, although the unbound plasma cefazolin exposure was less in the CPB-only group. Although we did not have a comparison group that did not undergo $\mathrm{CPB}$, in a piglet model of pediatric $\mathrm{CPB}$ subjects that underwent median sternotomy without $\mathrm{CPB}$ showed peak

TABLE 3. Percentage of time cefazolin concentrations were greater than different concentration targets

\begin{tabular}{|c|c|c|c|c|c|c|c|}
\hline \multirow{2}{*}{$\begin{array}{c}\text { Concentration } \\
\text { target }(\mu \mathrm{g} / \mathrm{mL})\end{array}$} & \multirow[b]{2}{*}{ SSI pathogen } & \multicolumn{2}{|c|}{ All subjects $(n=12)$} & \multicolumn{2}{|c|}{ CPB only $(n=5)$} & \multicolumn{2}{|c|}{ CPB + DHCA $(n=7)$} \\
\hline & & Unbound plasma & Skeletal muscle & Unbound plasma & Skeletal muscle & Unbound plasma & Skeletal muscle \\
\hline 2 & $M S S A$ & $100(100-100)$ & $100(99.2-100)$ & $100(100-100)$ & $100(100-100)$ & $100(100-100)$ & $100(99.2-100)$ \\
\hline 16 & $\begin{array}{l}\text { E coli, } K \\
\quad \text { pneumoniae }\end{array}$ & $93.6(68.9-94.6)$ & $55.5(1.7-86.1)$ & $69.8(65.1-93.1)$ & $84.2(74.6-91.9)$ & $94.4(89.8-97.9)$ & $11.2(0.5-55.5)$ \\
\hline 32 & $\begin{array}{l}\text { S epidermidis } \\
\quad \text { Enterobacter } \mathrm{sp}\end{array}$ & $43.7(32.7-51.0)$ & $0.0(0.0-66.7)$ & $16.3(12.0-47.4)$ & $42.1(0-72.6)$ & $45.6(40.5-57.4)$ & $0(0-0)$ \\
\hline
\end{tabular}

Data presented as median percentage (IQR). Each concentration target represents an estimated MIC 90 of bacteria potentially susceptible to cefazolin and known to cause SSIs in pediatric cardiac surgical patients. SSI, Surgical site infection; CPB, cardiopulmonary bypass; DHCA, deep hypothermic circulatory arrest; $M S S A$, methicillin-sensitive Staphylococcus aureus; E coli, Escherichia coli; K pneumonia, Klebsiella pneumonia; S epidermidis, Staphylococcus epidermidis. 
tissue concentrations of 15 to 30 minutes after administration, followed by a steady decrease in the concentration (T. Kilbaugh, unpublished data). Therefore, a second dose of cefazolin or, potentially, a continuous infusion of cefazolin might be important for maintenance of goal tissue concentrations of cefazolin, especially given the increased volume of distribution during CPB.

We demonstrated decreased tissue disposition of cefazolin into the skeletal muscle during DHCA despite the decreased plasma clearance and resultant greater overall plasma exposure (AUC) to the drug. We postulated that the decrease in diffusion of the unbound cefazolin into the muscle interstitium results from a combination of alterations in drug delivery and microcirculation secondary to induced circulatory arrest and deep hypothermia. Protein binding of cefazolin was less during the periods of DHCA and, if anything, would bias the findings more toward unbound cefazolin being more available for distribution into the surrounding tissue. Hypothermia, circulatory arrest, and operative time have all been described as risk factors for SSIs after pediatric cardiac surgery, with variable strengths of association. ${ }^{3-5,10,13,14}$ Although these factors all likely influence the tissue disposition of cefazolin, we are not able to comment on the relative importance of each factor.

In the present study, the subjects with the greatest plasma concentrations of total or unbound cefazolin did not necessarily have the greatest skeletal muscle concentrations of unbound cefazolin throughout the course of the surgical procedure (eg, subjects 1, 6, and 9). These differences were most profound during DHCA, suggesting that plasma levels might not be predictive of the skeletal muscle concentrations in all patients, highlighting one of the limitations of previous studies of prophylactic antibiotics in children undergoing $\mathrm{CPB}$ using the plasma level as a surrogate for the tissue concentration. ${ }^{20-23}$ Furthermore, despite the routine use of cefazolin for SSI prophylaxis in congenital cardiac surgery, only 1 published study has measured cefazolin in plasma, and that study was limited because it did not report the unbound cefazolin levels or tissue concentrations. $^{21}$

The most common side effect related to the microdialysis catheters was minor bleeding (defined as 1-3 drops of blood) at the insertion sites. No cases of significant bleeding (defined as $>1 \mathrm{~mL}$ of blood) nor of local or systemic infection related to the microdialysis catheter occurred. These results are congruent with the only dedicated microdialysis safety report in the pediatric data ${ }^{32}$ and demonstrate the feasibility and safety of using microdialysis during pediatric cardiac surgical procedures.

The study limitations included that we studied an infant population requiring cardiac surgery with $\mathrm{CPB}$ with or without DHCA. Thus, our results might not be applicable to all neonates, older children and adolescents, or patients with 2-ventricle physiology. In addition, the goal of our study was to measure the unbound cefazolin concentrations in the skeletal muscle during the surgical procedure; therefore, we restricted the sampling period to the intraoperative time. We did not fully characterize cefazolin clearance using modified ultrafiltration. No subject from our cohort developed an SSI; thus, we could not correlate any PK variability with the development of a postoperative infection.

The microdialysis catheters were placed in the deltoid muscle to avoid complications arising from interference in the operative field. Therefore, we cannot comment on local tissue concentrations closer to the surgical wound. However, 1 adult study showed that the tissue concentrations of cefazolin were lower when measured close to the surgical wound than at sites separate from the surgical site, ${ }^{30}$ again suggesting that our PD assessments were likely overestimates. The importance of achieving adequate tissue concentrations of prophylactic antibiotics for effectiveness against SSIs has been recognized. ${ }^{16}$ Studies in adult populations have linked tissue concentrations to wound infections ${ }^{33,34}$; however, no such data have been reported in published pediatric studies.

One recent large retrospective analysis suggested that a significant modifiable risk factor for the prevention of SSIs in pediatric patients is the appropriate administration of prophylactic antibiotics. ${ }^{35}$ Our results suggest that the current cefazolin dosing strategies could be flawed. The timing of prophylactic cefazolin administration and a second dose of cefazolin given on initiation of CPB are important considerations for infants undergoing cardiac procedures with $\mathrm{CPB}$, with and without DHCA. Depending on the local SSI epidemiology, in addition to optimization of SSI prevention bundles, the dosing of cefazolin with patients undergoing DHCA might need to be altered or another agent considered if gram-negative organisms constitute a high proportion of postoperative infections. The present study has provided a model for future investigations of different prophylactic antibiotic dosing regimens in pediatric surgical populations that should be designed to better understand patient variability and to develop evidence-based dosing recommendations that achieve defined PD targets.

\section{References}

1. van Saet A, de Wildt SN, Knibbe CA, Bogers AD, Stolker RJ, Tibboel D. The effect of adult and pediatric cardiopulmonary bypass on pharmacokinetic and pharmacodynamic parameters. Curr Clin Pharmacol. 2013;8: 297-318.

2. Buylaert WA, Herregods LL, Mortier EP, Bogaert MG. Cardiopulmonary bypass and the pharmacokinetics of drugs: an update. Clin Pharmacokinet. 1989;17: $10-26$.

3. Holzmann-Pazgel G, Hopkins-Broyles D, Recktenwald A, Hohrein M, Kieffer P, Huddleston C, et al. Case-control study of pediatric cardiothoracic surgical site infections. Infect Control Hosp Epidemiol. 2008;29:76-9.

4. Allpress AL, Rosenthal GL, Goodrich KM, Lupinetti FM, Zerr DM. Risk factors for surgical site infections after pediatric cardiovascular surgery. Pediatr Infect Dis J. 2004;23:231-4. 
5. Nateghian A, Taylor G, Robinson JL. Risk factors for surgical site infections following open-heart surgery in a Canadian pediatric population. Am J Infect Control. 2004;32:397-401

6. Mehta PA, Cunningham CK, Colella CB, Alferis G, Weiner LB. Risk factors for sternal wound and other infections in pediatric cardiac surgical patients. Pediatr Infect Dis J. 2000;19:1000-4.

7. Sarvikivi E, Lyytikäinen O, Nieminen H, Sairanen H, Saxén H. Nosocomial infections after pediatric cardiac surgery. Am J Infect Control. 2008;36:564-9.

8. Barker GM, O'Brien SM, Welke KF, Jacobs ML, Jacobs JP, Benjamin DK Jr, et al. Major infection after pediatric cardiac surgery: a risk estimation model. Ann Thorac Surg. 2010;89:843-50.

9. Murray MT, Krishnamurthy G, Corda R, Turcotte RF, Jia H, Bacha E, et al. Surgical site infections and bloodstream infections in infants after cardiac surgery. J Thorac Cardiovasc Surg. 2014;148:259-65.

10. Costello JM, Graham DA, Morrow DF, Morrow J, Potter-Bynoe G, Sandora TJ, et al. Risk factors for surgical site infection after cardiac surgery in children. Ann Thorac Surg. 2010;89:1833-42.

11. Ben-Ami E, Levy I, Katz J, Dagan O, Shalit I. Risk factors for sternal wound infection in children undergoing cardiac surgery: a case-control study. J Hosp Infect. 2008;70:335-40.

12. Kagen J, Lautenbach E, Bilker WB, Matro J, Bell LM, Dominguez TE, et al. Risk factors for mediastinitis following median sternotomy in children. Pediatr Infect Dis J. 2007;26:613-8.

13. McAnally HB, Cutter GR, Ruttenber AJ, Clarke D, Todd JK. Hypothermia as a risk factor for pediatric cardiothoracic surgical site infection. Pediatr Infect Dis J. 2001;20:459-62.

14. Sohn AH, Schwartz JM, Yang KY, Jarvis WR, Guglielmo BJ, Weintrub PS. Risk factors and risk adjustment for surgical site infections in pediatric cardiothoracic surgical patients. Am J Infect Control. 2010;38:706-10.

15. Kirby JP, Mazuski JE. Prevention of surgical site infection. Surg Clin North Am. 2009;89:365-89.

16. Bratzler DW, Dellinger EP, Olsen KM, Perl TM, Auwaerter PG, Bolon MK, et al. Clinical practice guidelines for antimicrobial prophylaxis in surgery. Am J Health Syst Pharm. 2013;70:195-283.

17. Müller M, dela Peña A, Derendorf H. Issues in pharmacokinetics and pharmacodynamics of anti-infective agents: distribution in tissue. Antimicrob Agents Chemother. 2004;48:1441-53.

18. Chaurasia CS, Müller M, Bashaw ED, Benfeldt E, Bolinder J, Bullock R, et al. AAPS-FDA workshop white paper: microdialysis principles, application and regulatory perspectives. Pharm Res. 2007;24:1014-25.

19. Joukhadar C, Müller M. Microdialysis: current applications in clinical pharmacokinetic studies and its potential role in the future. Clin Pharmacokinet. 2005; 44:895-913.

20. Hatzopoulos FK, Stile-Calligaro IL, Rodvold KA, Sullivan-Bolyai J, Del Nido P, Levitsky S. Pharmacokinetics of intravenous vancomycin in pediatric cardiopulmonary bypass surgery. Pediatr Infect Dis J. 1993;12:300-4.
21. Haessler D, Reverdy ME, Neidecker J, Brûlé P, Ninet J, Lehot JJ. Antibiotic prophylaxis with cefazolin and gentamicin in cardiac surgery for children less than ten kilograms. J Cardiothorac Vasc Anesth. 2003;17:221-5.

22. Masuda Z, Kurosaki Y, Ishino K, Yamauchi K, Sano S. Pharmacokinetic analysis of flomoxef in children undergoing cardiopulmonary bypass and modified ultrafiltration. Gen Thorac Cardiovasc Surg. 2008;56:163-9.

23. Knoderer CA, Saft SA, Walker SG, Rodefeld MD, Turrentine MW, Brown JW, et al. Cefuroxime pharmacokinetics in pediatric cardiovascular surgery patients undergoing cardiopulmonary bypass. J Cardiothorac Vasc Anesth. 2011;25:425-30.

24. Guidance for Industry: Bioanalytical Method Validation. Washington, DC: US Department of Health and Human Services, Food and Drug Administration, Center for Drug Evaluation and Research (CDER), and Center for Veterinary Medicine (CVM); 2001

25. Craig WA. Pharmacokinetic/pharmacodynamic parameters: rationale for antibacterial dosing of mice and men. Clin Infect Dis. 1998;26:1-10.

26. Andes DR, Craig WA. Cephalosporins. In: Mandell GL, Bennett JE, Dolin R, eds Mandell, Douglas and Bennett' Principles and Practice of Infectious Diseases. 7th ed. Philadelphia: Churchill Livingstone Elsevier; 2010.

27. Vella-Brincat JW, Begg EJ, Kirkpatrick CM, Zhang M, Chambers ST, Gallagher K. Protein binding of cefazolin is saturable in vivo both between and within patients. Br J Clin Pharmacol. 2007;63:753-7.

28. Hutschala D, Skhirtladze K, Kinstner C, Mayer-Helm B, Müller M, Wolner E, et al. In vivo microdialysis to measure antibiotic penetration into soft tissue during cardiac surgery. Ann Thorac Surg. 2007;84:1605-10.

29. Douglas A, Udy AA, Wallis SC, Jarrett P, Stuart J, Lassig-Smith M, et al. Plasma and tissue pharmacokinetics of cefazolin in patients undergoing elective and semielective abdominal aortic aneurysm open repair. Antimicrob Agents Chemother. 2011:55:5238-42.

30. Andreas M, Zeitlinger M, Hoeferl M, Jaeger W, Zimpfer D, Hiesmayr JM, et al Internal mammary artery harvesting influences antibiotic penetration into presternal tissue. Ann Thorac Surg. 2013;95:1323-9.

31. Wildschut ED, Ahsman MJ, Allegaert K, Mathot RA, Tibboel D. Determinants of drug absorption in different ECMO circuits. Intensive Care Med. 2010;36: 2109-16.

32. Hack A, Busch V, Gempel K, Baumeister FA. Subcutaneous microdialysis for children — safe biochemical tissue monitoring based on a minimal traumatizing no touch insertion technique. Eur J Med Res. 2005;10:419-25.

33. Forse RA, Karam B, MacLean LD, Christou NV. Antibiotic prophylaxis for surgery in morbidly obese patients. Surgery. 1989;106:750-6.

34. Zelenitsky SA, Ariano RE, Harding GKM, Silverman RE. Antibiotic pharmacodynamics in surgical prophylaxis: an association between intraoperative antibiotic concentrations and efficacy. Antimicrob Agents Chemother 2002;46:3026-30.

35. Shah GS, Christensen RE, Wagner DS, Pearce BK, Sweeney J, Tait AR. Retrospective evaluation of antimicrobial prophylaxis in prevention of surgical site infection in the pediatric population. Paediatr Anaesth. 2014;24:994-8. 